Article

\title{
Shallow Inclusion (or Integration) and Deep Exclusion: En-Dis-Abling Identities through Government Webpages in Hong Kong
}

\author{
Alex Cockain \\ Department of Applied Social Sciences, The Hong Kong Polytechnic University, Kowloon, Hong Kong; \\ E-Mail: alex.cockain@polyu.edu.hk
}

Submitted: 23 November 2017 | Accepted: 10 January 2018 | Published: 17 May 2018

\begin{abstract}
This article is primarily concerned with how government webpages in Hong Kong claiming to embrace social inclusion and provide services and support for persons with disabilities construct issues relating to disability. These texts are not read in isolation. Instead, they are considered in conjunction with discourse produced in several United Nations documents, especially the Convention on the Rights of Persons with Disabilities, to which Hong Kong is a signatory. These documents appear to both proffer and retract social inclusion in ways that complicate, if not undermine entirely, their purportedly inclusionary intentions. This article also reflects upon commentary produced by university students at a public university in Hong Kong responding to government discourse. Such focus upon 'non-disabled' readers reveals how texts do more than merely mediate pre-existing messages. Instead, they constitute a "social location and organizer for the accomplishment of meaning", thereby counting as "a form of social action" (Titchkosky, 2007, p. 27). Through the texts they conspire to make about disability, authors and readers become complicit in the production, maintenance, and reinforcement of non-disabled (or abled)/disabled identities and dis/ableist ideology in ways that implicate the entire population in exclusionary processes.
\end{abstract}

\section{Keywords}

barriers; dis/ableism; exclusion; Hong Kong; integration; non-disabled (or abled)/disabled identities; othering; rehabilitation; social inclusion; United Nations

\section{Issue}

This article is part of the issue "Global Perspectives on Disability", edited by Shaun Grech (The Critical Institute, Malta) and Karen Soldatic (Western Sydney University, Australia).

(C) 2018 by the author; licensee Cogitatio (Lisbon, Portugal). This article is licensed under a Creative Commons Attribution 4.0 International License (CC BY).

\section{Introduction}

This article is primarily concerned with how government webpages in Hong Kong ${ }^{1}$ claiming to embrace "social inclusion" (GovHK, 2016a) and provide "services and support for persons with disabilities" (GovHK, 2016b) construct issues relating to disability, although these texts are read in conjunction with other discourse. A wider corpus of discourse is relevant to this article because in 2008 the Hong Kong Special Administrative Region (hereafter, HKSAR) and the People's Republic of China (hereafter, PRC) became signatories to the United Nations Convention on the Rights of Persons with Disabilities (hereafter, UNCRPD), a human rights treaty intended to protect the "rights" and "dignity" of disabled persons. ${ }^{2}$ First, and most prominent, is the UNCRPD itself (UN, 2006). The Convention has eight guiding principles, although most relevant to this article is the intention to realize "[f]ull

\footnotetext{
${ }^{1}$ It is beyond the scope of this article to provide an overview of issues relating to disability in Hong Kong, both past and present. For such content, see Ngai, Wu and Chung (2018).

${ }^{2}$ As the UNCRPD homepage explains, the treaty and its optional protocol "was adopted on 13 December 2006 at the UN Headquarters in New York, and was opened for signature on 30 March 2007. There were 82 signatories to the Convention, 44 signatories to the Optional Protocol, and 1 ratification of the Convention. This is the highest number of signatories in history to a UN Convention on its opening day. It is the first comprehensive human rights treaty of the 21st century and is the first human rights convention to be open for signature by regional integration organizations. The Convention entered into force on 3 May 2008" (CRPD, n.d., emphasis added).
} 
and effective participation and inclusion in society" (UN, 2006, p. 5, emphasis added). Discourse on the UNCRPD homepage constructs the Convention as immensely significant and deploys metaphorical language to celebrate the crucial role of the UN in manufacturing this. For example, the Convention is proclaimed as taking "to a new height" the "movement" from:

Viewing persons with disabilities as 'objects' of charity, medical treatment and social protection towards viewing persons with disabilities as 'subjects' with rights, who are capable of claiming those rights and making decisions for their lives based on their free and informed consent as well as being active members of society. (CRPD, n.d.)

Second is the Initial Report of the HKSAR of the PRC under the UNCRPD (HKSAR, 2010). Third is the concluding observations on the initial report of China, adopted by the Committee at its eighth session (UN, 2012).

Echoing Robert McRuer's (2007, p. 5) discussion of the use of "independence" and "inclusion" within, and around, the disability rights movement, and the ways these are appropriated by the World Bank, this article reveals how "rhetorics of...inclusion mask" more exclusionary content, illustrating how texts can, as Najma Al Zidjaly (2012) also argues in an Omani context, "unintentionally harm social causes" (Al Zidjaly, 2012, p. 190). Although the texts to which this article is concerned appear to proffer social inclusion, they also contain exclusionary sub-text, or latent content that works to limit, and perhaps even retract this, thereby producing only a very shallow form of inclusion (that more closely resembles integration). However, texts do more than merely mediate pre-existing messages. Instead, they constitute a "social location and organizer for the accomplishment of meaning", thereby counting as "a form of social action" (Titchkosky, 2007, p. 27). Put differently, readers are implicated in the production of knowledge, and the exclusionary processes this is intertwined with, "because they must make the association in the act of reception" (Wodak, 2004 , p. 195). In so doing, readers become complicit in the production, maintenance, and reinforcement of nondisabled (or abled)/disabled identities and dis/ableist ideology. More specifically, after a brief discussion relating to methodology and ethics, this article first explores inclusionary and exclusionary discourse in these texts before focusing upon students' readings of this discourse. The article concludes by contemplating how this discourse might relate to, and what it might reveal about, wider commitments to social inclusion, or the lack thereof.

\section{Methodology}

This article's concern with the textual enactment of disability in, and through, government webpages has been informed by my reading of Tanya Titchkosky's (2007) discussion on Canadian government texts on disability (pp. 45-78, 145-176). Titchkosky argues these not only "construct disability as a problem" but also "sponsor solutions to the problem they have constructed" (2007, p. 145). Language, like representation, is not, accordingly, incidental to the world. Instead, it is productive and words, as well as the discourse they contribute to, as Michel Foucault (1969/2002) has so evocatively claimed, have the capacity to "form the objects of which they speak" (p. 54). My recognition of the power and contingency of language and commitment to destabilize this is informed by principles associated with critical discourse analysis (hereafter, $C D A$ ), post-structural literary theory (Eagleton, 1983/2008, pp. 110-130) and, albeit to a lesser extent, the work of Jacques Lacan. As Ruth Wodak (2004) explains, CDA attempts to demystify ideologies and power "through the systematic investigation of semiotic data" (pp. 185-186). Post-structural theory, meanwhile, illuminates how ideological attempts to "draw rigid boundaries", typically through binary oppositions of one kind or another, "are sometimes betrayed into inverting or collapsing themselves" (Eagleton, 1983/2008, p. 115). Reference is made to Lacan in order to illustrate how these struggles, or 'play', are sutured by certain devices, namely a "point de capiton", or "quilting point", which anchor meanings, thereby preventing a shapeless mass of meaning from moving too freely: knotting the signified and signifier together in order to produce "the necessary illusion of a fixed meaning" (Evans, 1996, p. 151).

More specifically, I have acted in the manner of a social semiotician, collecting, documenting and cataloguing texts for the purpose of investigating them (Van Leeuwen, 2005, p. 3). Although my initial intention was to focus solely upon HKSAR discourse, it became apparent this had to be contemplated in conjunction with a wider corpus of discourse, not least because of the links that bind these documents with others in intertextuality in ways that productively problematize the taken-forgranted notion of a text as having discrete boundaries. Having limited my study to analysis of this corpus of words, I proceeded from simple coding, paying attention to the frequency (and absences and omissions) of words, to thematic coding, albeit while being methodologically attached to the notion that "there is no single set of categories waiting to be discovered" and, crucially, that there "are as many ways of 'seeing' the data as one can invent" (Dey, 1993, p. 117). This article also explores elicited written commentary produced by apparently 'non-disabled' university students at a public university in Hong Kong responding to government discourse. Such an analysis has also proceeded from the identification of absences and presences through simple 'in-vivo coding' to more speculative interpretation of the nature, and implications, of students' readings.

\section{Ethical Considerations}

The methodology deployed in this article raises ethical issues, of which two are especially salient. First is my us- 
age of students as initially uninformed research participants and, related to this, my decision not only to 'push' critical readings (which might have induced ontological anxieties for some) but also explore their commentary not for their true feelings-as indeed had been my intention when I initially asked them-but instead as a corpus of discursive practices. Martyn Hammersley (2014) focuses upon such ethical dilemmas when applying constructionist forms of discourse analysis to interviews, observing that attempts to remedy "deception" might be counterproductive because informants could "become self-conscious about the language they use, perhaps editing it on the basis of some notion of 'good talk', or at least trying to avoid "bad talk'” (p. 532). I share such a view, to which I would add that boundaries between ethical and unethical research practice-like the identities to which this article is concerned-are imprecise. Even though "sticking rigidly" to codes and guidelines "cannot ensure...research is ethical" (Ali \& Kelly, 2012, p. 73), I have attained students' informed consent, albeit only after the event. Students have also been given pseudonyms, thereby preserving anonymity. I have also narrated such ethical transgressions-whether 'real' or imagined, and to myself if not others-as being an unavoidable repercussion of my efforts to elaborate upon "the non-disabled psyche" and illustrate how, as Dan Goodley (2012) puts it, "non-disabled people and disablist culture...subjugate...disabled people" (p. 181).

Causing me more, and as yet unresolved, ethical anxieties is that my efforts to articulate the exclusion of disabled persons might, inadvertently, have replicated this silencing. This relates to the fact that this article explores elicited written commentary produced by purportedly 'non-disabled' university students and does not, as perhaps some readers might expect this article could (and perhaps should) have done, solicit the views of 'disabled' persons. In so doing, I am, arguably, complicit with the structures and discourses I seek to critique. ${ }^{3}$ Although I contemplated such an absence at the outset of writing this article, telling myself this omission, or aporia, would, as it still will be, filled in a subsequent project focusing upon 'disabled' persons' readings, so conspicuous is this absence now it almost seems an "absent presence", albeit one that might implicitly inform the arguments developed in this article. ${ }^{4}$ Despite such reservations, it is hoped the structure and content of the article, as it is now, may allow-and perhaps even force contemplation of how persons-including myself and others (perhaps even some readers) implicated in this article-are, like the wider population to which Fiona Kumari Campbell (2012) refers, implicated in "the production, operation and continuation of ableism" (p. 215). Importantly, I am willing, as Judith Butler (1997) puts it, "to be undone by the critique that he or she performs" (p. 108). ${ }^{5}$

\section{Inclusionary and Exclusionary Discourse}

The paragraphs below analyse HKSAR discourse, especially but not exclusively documents entitled Embracing Social Inclusion (hereafter, ESI) and Services and Support for Persons with Disabilities (hereafter, SSPD), and the equivalent versions of these pages in both traditional and simplified Chinese characters (GovHK, 2016a, 2016b, 2016c, 2016d, 2016e, 2016f). ${ }^{6}$ After recognizing inclusionary content, the paragraphs explore the more voluminous sub-text, namely content that is "backgrounded, hidden, repressed, or unconscious rather than explicit" (Chandler \& Munday, 2011, p. 413).

\subsection{Inclusionary Discourse}

ESI and SSPD contain straightforward expressions of government beneficence. These documents make inclusionary statements, such as: "The Government is committed to enhancing an inclusive society, so that all individuals can enjoy equality and respect in different areas of life" (GovHK, 2016a).

Meanwhile, the Initial Report not only states HK\$13 million had been spent on "publicity campaigns to promote the inclusion of people with disabilities" (HKSAR, 2010 , p. 31) but also that local offices of the Social Welfare department had organized activities to "promote...social inclusion and the spirit of the Convention at district level" (p. 33). Most emphatically, perhaps, is the claim that "various habilitation and rehabilitation programmes" had been implemented "to enable persons with disabilities to attain and maintain maximum independence, full physical, mental and social ability and full inclusion and participation in all aspects of life" (HKSAR, 2010, p. 152, emphasis added).

Such unambiguous declarations repeat, almost verbatim, the inclusionary intentions of Article 1 in the UNCRPD, namely:

To promote, protect and ensure the full and equal enjoyment of all human rights and fundamental free-

\footnotetext{
${ }^{3}$ In one regard, the absence, or lack, of 'disabled' persons in the class might highlight exclusions and/or the ways in which persons might be compelled to 'pass', thereby assimilating themselves with ableist normativity. Such tendencies to exclude-rather than include-might be even more pervasive, entrenched and institutionalized. For example, David Mitchell and Sharon Snyder (2015) claim that "even highly funded research and policy organizations devoted to the social integration of disabled people... have actively resisted the most basic form of barrier removal" (p. 64). Equally, Henri-Jacques Stiker (1997) has referred to institutional resistance to sharing the world of disability with disabled people (p. 11).

${ }^{4}$ Jacques Derrida (1976) writes, in ways that might be pertinent to this, that: "The presence that is thus delivered to us...is a chimera....The sign, the image, the representation, which come to supplement the absent presence are the illusions that sidetrack us" (p. 154).

${ }^{5}$ Butler (1997) writes that for "the ' $I$ ' to launch its critique, it must first understand that the ' $\mathrm{l}$ ' itself is dependent upon its complicitous desire for the law to make possible its own existence" (p. 108).

${ }^{6}$ It is beyond the scope of this article to engage exhaustively with the entire content of these texts. Instead, this article gravitates toward 'problematic' content. The original, and complete, texts from which these words and sentences have been extracted can be found by following links included in the references at the end of this article (see, for example, CRPD, n.d.; GovHK, 2016a, 2016b, 2016c, 2016d, 2016e, 2016f; HKSAR, 2010; UN, 2006, 2012).
} 
doms by all persons with disabilities, and to promote respect for their inherent dignity. Persons with disabilities include those who have long-term physical, mental, intellectual or sensory impairments which in interaction with various barriers may hinder their full and effective participation in society on an equal basis with others. (UN, 2006, p. 4, emphasis added)

HKSAR discourse not only echoes the core ethos of the UNCRPD (cited in the introduction to this article) but also appears to accord with the numerous principles and obligations identified in CRPD (n.d.), such as awarenessraising (p. 8), accessibility (p. 9), habilitation and rehabilitation (p. 19) and participation in political and public life (p. 21). Such intertextuality between the UN and HKSAR discourse is unsurprising given the latter was a signatory to the UNCRPD. Significantly, this discourse, as Campbell (2012) explains, formulates disability in ways that transcend the "functional and medical orientation of traditional disability models" (p. 221), reflecting that "causes of disability...are external to individual bodies" (Grue, 2009 , p. 306). Consequently, the acknowledgement by HKSAR and the UN of the barriers emerging because of attitudes might indicate a "spread of sociopolitical definitions" and a "shift away from medical knowledge...in disability discourse" (Grue, 2009, p. 307), although subtext complicates, and perhaps even undermines entirely, such inclusionary discourse.

\subsection{Sub-Text}

That latent and ostensibly "out of sight" meanings are not, as Martha Helfer (2011) claims, necessarily "deeply concealed in dark, cavernous recesses of a literary crypt...[but] hidden all too obviously...in the open" (p. xiii) is evident here. In fact, the most obvious feature of ESI is the proliferation of positive words collocated with government (Figure 1) in addition to the "Embracing" deployed in the title of this document. Such frequency is even more noticeable given the brevity of the text.

Such discourse on ESI unequivocally works to create a positive representation of their 'own' group, a strategy which is involved in the justification of inequality, as Van Dijk (1993) explains, especially when this works in conjunction with "the negative representation of...Others" (p. 263). Admittedly, the 'positive' representation of government is more obvious and is achieved through a chain of discourse which constructs an active and beneficent subject collocated with "the material process, or 'processes of doing' type" of verb (Flowerdew, 2012, p. 55). These signify some 'material' or visible tangible change in the flow of events or the environment through actions made possible through government volition. Accordingly, social inclusion, like the production of disability (in UN discourse) is registered as an 'evolving' concept, albeit one that, crucially, relies upon top-down, paternalistic, interventions to realize. The acting subject of these verbs is government (e.g., the "government is com-

$\begin{array}{ll}\text { - committed } & \text { - sponsors (2) } \\ \text { - enhancing } & \text { - facilitate } \\ \text { - enjoy (twice) } & \text { - protects } \\ \text { - outlines } & \text { - access } \\ \text { - integrates (7) } & \text { - find } \\ \text { - provided (10) } & \text { - operated } \\ \text { - develop } & \text { - choose } \\ \text { - become } & \text { - attend } \\ \text { - receiving } & \text { - enters } \\ \text { - benefit } & \text { - covers } \\ \text { - given } & \text { - admits } \\ \text { - employ } & \text { - encouraged } \\ \text { - promote } & \text { - participate } \\ \text { - published (3) } & \text { - organized } \\ \text { - help (6) } & \text { - funded } \\ \text { - adapt } & \end{array}$

Figure 1. Positive verbs, and noun forms, in ESI.

mitted to"). However, this is often concealed through auto-passivization (e.g., to "help disabled persons plan their journeys, the Transport Department has published"). This transforms active sentences into passive ones. However, disabled people are more violently passivized as recipients of nouns (support, etc.). Such passivization makes disabled persons appear as "objects" devoid of agency, an "obfuscation" which might, as Fairclough (1989/2015) claims elsewhere, be "ideologically motivated" (p. 140), as I later explain. Through the combination of words into sentences, relatively conventional and culturally coded symbolic meanings emerge which are, as the next part of this article reveals, accessible to readers. However, this narrative, unlike that previously identified, constructs an individualized account that establishes barriers exist inside disabled persons and because these cannot be overcome independently the government, ipso facto, acts on disabled persons' behalf. This discourse contravenes the processual model of disability espoused in the UNCRPD and the HKSAR Initial Report. However, the UN do not acknowledge such disregard, even though after 48 lexical units under the heading of "positive aspects" in the UN response to the HKSAR Initial Report, 1496 words are clustered under subheadings associated with "areas of concern and recommendations" (UN, 2012, pp. 8-11), a silence which further complicates, and disturbs, purportedly inclusionary intentions.

\subsubsection{Othering}

Stuart Hall (1997/2013) has lucidly explained how representation works by marking differences which are constructed through language by way of binary oppositions, one of which is "dominant": a power dimension in discourse that might be captured by writing white/black, men/women, British/alien, and so on (p. 225). As Hall (1997/2003) explains with reference to the work of Mary Douglas, stable cultures "require things to stay in their appointed place" and that what "unsettles culture is 
'matter out of place'...a sign of pollution, of symbolic boundaries being transgressed" (p. 226). Such pollution is swept up or thrown out, thereby restoring order, all of which "leads us, symbolically, to close ranks, shore up culture and to stigmatize and expel anything...defined as impure, abnormal" (Hall, 1997/2013, p. 237, emphasis added). To the categories to which Hall refers, it is necessary to add non-disabled (or abled)/disabled. Although seemingly innocuous, the use of "their", applied to "people with disabilities" 10 times within ESI and SSPD, is instructive (GovHK, 2016a, 2016b). First, this increases psychic distance, contrasting markedly with the complete absence of 'you', or even 'we', which would, as Fairclough (1989/2015) suggests elsewhere, be more "inclusive" (p. 143). Second, 'their' covertly erases disabled persons from, or places them outside, the text which, implicitly, addresses supporters-family members and so on-who, therefore, mediate between the text, thereby protecting, or buffering, other readers (perhaps like the students whose readings are discussed during the next part of this article) from disabled persons. Third, albeit only perhaps implicitly (or through an allusion), 'their' seems to speak to and on behalf of a 'non-disabled' unity defined through a reduced, oversimplified and deficient 'disabled' other. Such processes as passivization and the absence (or erasure) of disabled persons inside the documents combine to make disabled persons, like those to whom Anita Ghai (2006) refers, appear "dis-embodied because...constructions around them...threaten to create a total invisibility of the disabled individual" (p. 147). Consequently, disabled persons likely seem even more reliant upon either supporters or the already self-constructed benevolent government. Such forms of othering combine to deny ways of thinking about the "agentive" (Mitchell \& Snyder, 2015, p. 1), "leaky" (Shildrick, 1997, p. 10) and "lively materiality" of disability (Mitchell \& Snyder, 2015, p. 1). Consequently, these texts might be viewed as reinforcing, rather than offering alternatives to what Robert McRuer (2006) calls "compulsory able-bodiedness", namely the notion that "able-bodied identities...[and] perspectives, are preferable and what we all, collectively, are aiming for" (p. 372, cited in Mitchell \& Snyder, 2015, p. 3). However, these documents not only 'other' disabled persons. In fact, even the offer of "services which help people with disabilities, ethnic minorities, new arrivals and the underprivileged to integrate into the community" (GovHK, 2016a) conflates disparate persons, identities and groups into an undifferentiated morass of otherness, thereby constituting violently exclusionary discourse.

\subsubsection{Inclusion...or Integration}

In HKSAR discourse, there is slippage or parapraxis between 'inclusion' and 'integration', gongrong and ron- gru in the simplified Chinese version of this document (GovHK, 2016c). In fact, with the exception of the title, integration is the term used (Figure 1). In ordinary discourse, such terms are used interchangeably. In disability studies discourse, however, these terms possess different connotations. As Colin Cameron (2014) explains, inclusion involves "the creation of settings in which difference is encouraged and valued" whereas integration typically implies disabled people must "become 'more like' non-disabled people in order to get acceptance" (p. 79). Crucially, although SSPD states there are a "wide range of rehabilitation services...available...to help people with disabilities to develop their physical, mental and social capabilities to the fullest possible extent" (GovHK, 2016b, emphasis added), these only relate to training and transport. Moreover, training is restricted to "working capacity" and "employment" (GovHK, 2016b). This not only suggests a neoliberal interpretation but also an assimilationist model of inclusion. Significantly, these texts, and the 'services' they mention, resemble those practices of "neoliberal disability tolerance" that Mitchell and Snyder (2015) refer to as inclusionism, "a term specifically associated with disabled bodies operative in the policy world of neoliberalism" (p. 4). These services, nevertheless, fall short of offering what Mitchell and Snyder (2015) call "meaningful inclusion" that necessitates "disability becomes more fully recognized as providing alternative values for living that do not simply reify reigning concepts of normalcy" (p. 5, original emphasis). Such 'inclusion' is, therefore, closer to definitions of integration within disability studies discourses and might even exemplify what Mitchell and Snyder (2015) call disability's "grudging admission to normative social institutions through inherently neoliberal forms of redress" (p. 35).

It seems, furthermore, that inclusion comes with conditions and significantly that deviating too far from 'normal' behaviours invariably results in exclusion. On ESI, for example, it states children with "special needs enjoy equal opportunity" to receive education in publicsector ordinary schools but "those who have more complex needs or whose disabilities are so severe that they cannot benefit from education in mainstream schools receive education in public-sector special schools" (GovHK, 2016a, emphasis added). Such discourse locates barriers to social inclusion unambiguously inside disabled people rather than in the incapability of structures to include, or admit, them. This discourse functions to obscure the social mechanisms involved in social exclusion and, more generally, the ways in which "society" acts "as an oppressive disabling force" (Thomas, 2007, p. 53). A medical model of disability underpins this discourse, acting as an "anchoring point" or "point de capiton" which stops "incessant sliding of the signified under the signifier" thereby stabilizing and fixing meanings, interpretations and relationships (Chandler \& Munday, 2011, p. 393). ${ }^{7}$

\footnotetext{
${ }^{7}$ Although the UN notes "the prevalence of the medical model of disability in both the definition of disability and the enduring terminology and language of the discourse on the status of persons with disabilities" in their report addressed to the PRC (UN, 2012, p. 2), this is conspicuously absent in the section addressed to HKSAR: an absent presence.
} 
Crucially, such a discourse not only enables "normalcy", and "'normal' social structures and artifice, to remain unquestioned" (Titchkosky, 2007, p. 165) but also displaces the onus from 'non-disabled' to 'disabled' people, implying they rather than society need to change (Cameron, 2014, p. 79) while not disturbing, and perhaps even reinforcing, the non-disabled (or abled)/disabled binary. Put differently, this seemingly innocuous sentence presents an assimilationist condition: either effect integration through normalization or become segregated in a special school. This means that the inclusion' of disabled people unequivocally demands a contradictory notion, namely "denying...differentness, their right to be...just the way they are" (Ravaud \& Stiker, 2006, p. 925).

These documents not only produce a narrow, shallow, version of social inclusion but also a limited definition of rehabilitation. ${ }^{8}$ These interrelate with, thereby reinforcing, each other, by virtue of both being located in a medical model of disability that functions to fix meanings. Although rehabilitation refers to a process, or processes, enabling disabled persons to "interact with their environments" (Albrecht, 2015, p. 420), in contrast to the expansive notions of barriers in UN discourse, HKSAR discourse limits these to physical and environmental barriers (e.g., the steps (not) going into a building, etc.) and does not therefore recognize socially constructed barriers, such as attitudes. Put differently, within HKSAR discourse rehabilitation focuses upon "the individual as a private entity" and therefore on the nature of a person's impairments, rather than on the "expectations and structures of the society and the community as a whole" (Albrecht, 2015, p. 421). Even the provision of transport on SSPD (called a Rehabus) while ostensibly realizing commitments to provide rehabilitation, albeit in only a bare form, can be read as perpetuating processes of segregation and, therefore, promoting exclusion rather than inclusion. This is because this conspires to remove, and erase, disability from places of quotidian life rather than, for example, working to remove attitudinal barriers, thereby enabling both 'non-disabled' and 'disabled' persons to use existing forms of transportation concurrently. The Rehabus might, therefore, be regarded as an act of dissociation. Admittedly, such discourse and the policies they become implicated in making seem not as extreme as to resemble an elimination model of exclusion (Ravaud \& Stiker, 2006, p. 925). Instead, they articulate an intermingling of "segregation" (or sequestration), "assistance" and "marginalization" models (Ravaud \& Stiker, 2006, p. 926).

\section{Ways of Reading}

The paragraphs below present an invariably partial and selective account of students' commentary reflecting upon HKSAR discourse in ESI and SSPD. The views of approximately 90 students were requested, although only 56 were submitted. A total of 14,000 words were produced.

\subsection{Beneficent Government and the Robustness of the Non-Disabled (or Abled)/Disabled Binary}

The discourse students most commonly produced not only recognized government's benevolence but also their role in facilitating a socially inclusive society. Students' commentary was, more generally, populated by relatively utopian visions (e.g., "society is full of love") of Hong Kong and one of the most prevalent words within the corpus of students' discourse was "positive", collocated with "ideas", "attitudes" and "words". One student from mainland China talked, for example, of the "kind language" which, she claimed, could "enlighten people with sympathy and comfort", even going so far as to suggest government discourse had altered her opinion of them. "As a student from mainland China, I used to think I should adapt to university life myself", she explained, "but now I feel the government cares about all minority groups". Chen's commentary might exemplify students' positive discourse:

I think the government is trying to produce and send a very clear message that they want to do their best to take care of everyone in Hong Kong. They are trying to send the message to the public that the government will take care of everyone, and that there is no need to worry even if you are disabled. These words make me feel the government is really trying to look after people in need, and that they are willing to support those people and try to make their lives more convenient or to try to help people adapt to a new environment. I think the message the government is trying to send is clear and I feel positive about the words.

Such tendencies to read government discourse at face value was at first surprising and disappointing since students' discourse had been initially solicited for pedagogical purposes, namely to apply principles associated with CDA subsequent to a class in which they had been introduced to them. In short, students had been actively encouraged to not only search for bias but also denaturalize and deconstruct language and I was disappointed when they had not collectively done so. Such readings, nevertheless, seem to unequivocally indicate the extent to which the social conditions, or "the underlying conventions" (Fairclough, 1989/2015, p. 60), which make possible both government and students' own discourse are naturalized. For example, students' discourse like "the government is doing its best", "disabled people need help", "there is not much else which can be done", etc., reproduce, and therefore reinforce, individualized 'per-

\footnotetext{
${ }^{8}$ Mitchell and Snyder (2015) observe that although rehabilitation often "refers to a productive process of recovery leading to a return to approximations of normative embodiment (and, ultimately, employability)...the term suggests something less optimum. Cultural rehabilitation refers to normalization practices at work within the neoliberal era through which nonnormative (i.e., nonproductive) bodies become culturally docile" (p. 205).
} 
sonal tragedy' models of disability which leave social structures unquestioned. In fact, "help" was the most frequently used word in the mass of text produced by students, appearing 90 times (out of a total corpus of 14,000 words), e.g., "the government play[s] an important role to help people", "disabled people are helpless", "disabled people need the most help", etc. Alternatively, albeit perhaps related to this, students' readings might reveal how dis/ableist ideology and discourse is so "normal", "natural", and taken-for-granted it has become "invisible" (Jaworski \& Thurlow, 2011, p. 21): even when students were specifically required to search for it. In fact, several students, and one male student in particular with whom I had hitherto enjoyed a good relationship, appeared frustrated and even quite irritated by my "cynical" efforts, as he put it, to incite students to re-read their readings more critically. Admittedly, students' propensities to speak government discourse might also be because of either their instrumental tendencies ${ }^{9}$ or resistance to me, and perhaps a combination thereof rather than the power (or taken-for-grantedness) of these discourses per se. It is, nevertheless, compelling to read these processes as illustrative of recontextualization, namely "the movement of parts or elements of...texts out of their original context...into a different context" (Fairclough, $1989 / 2015$, p. 38), in ways that reinforce them. Equally, students' readings might indicate government power: as Norman Fairclough (1989/2015) explains "the power to project one's practices as universal and 'common-sense', is a significant complement to economic and political power...exercised in discourse" (p. 64).

Although government discourse invariably shaped students' readings, they were not 'prisoners of discourse', even if they appeared to speak government discourses "as if they were their own", as Bronwyn Davies (2003) puts it in another context (p. 14, original emphasis). In fact, rather than reading students' tendencies to repeat government discourse as being resultant from the irresistible force of discourse, it might be more plausible to view students as being partly complicit with them, whether consciously or unconsciously. Such complicity might be because elements of already elaborated upon government discourse made firm distinctions between non-disabled (or abled)/disabled identities in ways which privilege the former over the latter in this binary. Because students' own identities are invested in this binary, they might be amenable, and receptive, to those previously elaborated upon allusions, located, according to my reading, in the sub-text of government discourse, albeit while being maintained, and perhaps even consolidated, by students' readings. As Wodak (2004) explains, allusions not only "suggest negative associations without being held responsible for them" but also "depend on shared knowledge": the "person who alludes to something counts on preparedness for resonance, i.e., on the preparedness of the recipients consciously to call to mind the facts that are alluded to" (p. 195). Importantly, allusions exist as a kind of repertoire of collective knowledge (Wodak, 2004, p. 195).

\subsection{Questioning the Non-Disabled (or Abled)/Disabled Binary and Aesthetic, and Ontological, Nervousness}

Nevertheless, doubts insinuated themselves into some students' discourse. In some cases this expanded in ways that evoked Michel Foucault's (1977/1995) evocative description of the "confused horror" which "spread from the scaffold" at the start of Discipline and Punish enveloping persons in shame (p. 9). Lam, a female student, described how when reading the Chinese terms (as opposed to the English) she found them neither "appropriate" nor "polite", as she put it. She was most concerned with the term canji, a generic term connoting 'disabled', 'handicapped' or 'deformed', despite being aware that the term has, as she put it, been adopted by the UN and is, as Emma Stone (1999) points out, officially endorsed and "an apparently new and neutral term" (p. 136). Her unease was even more poignant given that she could not, as she put it, "think of a more suitable term", indicating deficiencies in, and with, existing discourse. ${ }^{10}$ Lam was, it seemed, preoccupied by language-as indeed I had wanted her and her classmates to be-and its capacity to label. She commented, for example, about how negative labels attach to persons, and groups, not only guiding attitudes and behaviour but also, as Swain, French and Cameron (2003) observe, becoming embroiled in processes of surveillance and segregation, in ways which disable persons (p. 12). She was, in short, questioning the invisibility of discourse and consequently her common-sense distinctions between non-disabled (or abled)/disabled were becoming challenged. This seemed to make her uneasy, perhaps because such ruminations threatened her own 'non-disabled' identity. As Lam explained:

Words can influence how people think. If I am not wrong, I suppose this is the hidden power in discourse. It is often not clear and not apparent to people, and hard to identify in our everyday life. However, it has a big impact on our world, as words can influence and even change our thoughts without us knowing. By using certain words on the Chinese webpage, these people [emphasis added] sound not normal. It will make the public feel pity and sympathy for them, but also superiority at the same time.

In effect, Lam had engaged with the sub-text of government discourse. She was also witnessing the ways in

\footnotetext{
${ }^{9}$ While beyond the scope of this article, students often appear to me, and themselves (if their self-assessments in both semi-structured interviews and more informal contexts can be taken as revealing their true feelings), as being motivated by instrumental reason. Their repetition of government discourse almost verbatim might, accordingly, be seen as tactics deployed to complete the task with the minimum amount of effort.

10 Lam's discontent was, according to my reading, pertinent given canji is comprised of two characters, namely can, which encompasses such meanings as 'incomplete', 'deficient', 'remnant', 'ferocious', 'barbarous' and ji, or 'disease', 'illness' and 'suffering'.
} 
which 'the non-disabled imaginary' appears intent upon elongating distances, both physical and psychic, between 'us' and 'them', or 'self' and 'other', through the production, maintenance and consolidation of a non-disabled (or abled)/disabled binary in order to reinforce what Bill Hughes (2012) poignantly terms "the emotional infrastructure of ableism" (p. 68). Her preoccupation with words reveals how despite living in dis/ableist cultures and societies, processes of internalizing these ideologies are not complete. For her, ableist words "obstinately refuse, sounding alien in the voice of the one who enacts them through speech", as Campbell $(2008$, p. 157) puts it elsewhere: even when it was her speaking them. Yip, meanwhile, seemed not only exasperated, and perhaps even angry, at language's lack of power to ameliorate the circumstances in which it is spoken, or written but also cynical about government discourse:

The government acts like a giver, a provider, to help with the 'reintegration' of the disabled into society, to help them to get a 'normal' life like the rest of us. Perhaps the word 'disabled' itself already suggests a certain kind of disapproval, saying they are 'not able'. Words on these pages try to be as fair as they can but still they cannot cover the shred of empathy in them, victimizing those with disabilities by offering them 'support'. The word support implies a patronizing perspective towards disabled because help is offered by those with most power. The concessions provided to them separate the disabled from the rest of us. Just like the elderly, those labelled 'disabled' are said to need help to 'reintegrate' as if they were not in this society with us together. While the services offered aim to help disabled people cope with the challenges they find in daily life, the use of words in these paragraphs already groups the disabled and separates them from the rest of the society.

\subsection{Reducing or Removing Ontological Anxieties}

Readings by Lam and Yip not only register but also generate unease in ways that demonstrate how encounters between 'non-disabled' and 'disabled' persons may become a "primary scene of extreme anxiety" (Quayson, 2007, p. 17) even when these occur in mediated forms. These emerge when students confront the instability of, and imprecisions associated with, both language and self. Such readings might ostensibly indicate the fragility of power and hegemony, and the precariousness of dis/ableist ideology and the identities capable of being produced (and denied) by them. Nevertheless, given the anxieties they engender, it seems plausible students work to assuage, or expunge, these oppositional, and not only troubled but also troubling, readings of government discourse. In fact, even in short fragments of discourse, discursive knots of one kind or another were unravelled or sutured internally, in ways that re-privileged, and reinforced dis/ableist discourse and non-disabled (or abled)/disabled identities. Having glimpsed, albeit perhaps fleetingly, the leakiness of seemingly robust classificatory systems constructed through discourse, they needed, in effect, to be refortified. For example, Chiu had been, according to my reading, extremely disturbed by her engagement with government discourse, ruminating upon how there was "no definite taxonomy" between 'abled' and 'disabled' persons and that it is "only we who try to differentiate or, in other words, isolate people". However, her reading of government discourse still, ultimately, functioned to contain anxieties. She claimed, for example, that even though "minorities face innumerable difficulties", they are "lucky" to be born now and in a context in which there is a "government to help them, and fight for them". Chiu thereby enabled herself to conclude by articulating a positive view of government surmising their actions as being correct. Ostensibly Wong was entirely incredulous to government discourse, a scepticism which might partly be a consequence of her having attended a class in media theory that spent significant time developing tools with which to critically read media representations. Wong claimed these webpages painted an "overly exaggerated and beautified" picture, albeit one that did not deceive her. Nevertheless, only several sentences earlier she talked of feeling "comforted", "at ease" and, significantly, claimed these webpages ensured she did not need to do anything or feel guilty because "they [disabled people] are already well-protected, things are fine, they are perfectly good", although such words might, admittedly, have been spoken, or written, with the world weariness of a cynic.

\section{Concluding Thoughts}

This article has explored how purportedly inclusive discourse not only deflects away from the population it seems intended to address but also gives persons who engage with this discourse means through which they might reassure themselves that disabled persons are being taken care of while at the same time securing, and holding in place, non-disabled (or abled)/disabled identities. While this article has primarily focused upon discourse produced in Hong Kong, this exists in relation to that produced by the UN in ways that suggest international organizations are complicit in the co-production of what Campbell (2012) calls "geodisability knowledge" (p. 218). The discourse explored in this article seems to suggest, at best, only a very limited commitment to social inclusion and, perhaps, indicates far greater efforts to secure, and stabilize, non-disabled (or abled)/disabled binaries. In fact, these documents, despite their selfcongratulatory tone, reinforce rather than weaken the ontological consistency of such categories. Related to this, while not entirely announcing social inclusion as a finished project, texts like CRPD (n.d.) not only celebrate progress but also collocate it with the government and international organizations in ways that might indicate the insidious expansion of the "practitioners of normaliza- 
tion rather than the inclusion" (Mitchell \& Snyder, 2015, p. 71) of disabled persons. In so doing, the aspiration of social inclusion is appropriated, while being re-defined, and constructed as something that can be achieved by and through politicians and policy-makers while obscuring, and perhaps even erasing entirely, the notion that inclusion is only realizable through either "a process of struggle that has to be joined" (Oliver, 1996, p. 90) or conscientization. The effect of incorporating social inclusion into official discourse is, as John Fiske (1987/2006) argues in the context of signs of the 'new woman' and 'patriarchy', "to defuse any threat it might contain and to demonstrate" the capacity of ableism to "accommodate potentially radical movements within the existing power structure" (p. 38). Such appropriation also debilitates recontemplation of those normalized, naturalized, takenfor-granted and 'unthought' categories that unequivocally act, as Scott Lash (1994) explains with reference to Pierre Bourdieu, as "preconditions of our more selfconscious...practices" (p. 154).

However, readers are also implicated in such processes or meaning making and, as much as if not more so than the documents with which they engage, hold the ideological system in place. In so doing, readers function like the Lacanian "point de capiton" which (or who) "fixes...meaning", submitting them to some code (Žižek, 1989, p. 103) effecting or making it have a stable meaning. One corollary of such an interpretation is that ideology operates through people who "iron out' contradictions...in ways which accord with the interests and projects of domination" (Fairclough \& Chouliaraki, 1999, p. 26). In this regard, these ostensible "struggles" in and through discourse might necessarily be reconceptualized as figurative skirmishes in which dominant dis/ableist ideologies and discourses not only emerge unscathed but also reconsolidated, even being fortified by and through seemingly oppositional readings. Through such processes with which readers are complicit, and echoing observations on racism, non-disabled (or abled)/disabled identities might even be galvanized "with the intentional or unintentional support of the entire culture" (Jones, 1972, p. 172). This is because a kind of "aesthetic nervousness" (Quayson, 2007) is induced when readers like Lam confront (or are confronted by) what Judith Butler (2000) terms an "unassimilable remainder" (p. 24) as disability "escapes the confines of its negative ontology" even while discourse produces it (Titchkosky, 2007, p. 126). The discourse to which this article has referred might, therefore, be read as working to manage (or contain) such ontological anxieties and as strengthening rather than weakening what David Bolt (2012) has termed "critical avoidance" (p. 287). However, to "leave one's thought in a state of unthought" is, as Bourdieu (1992) observes with regard to the ways in which the social world constructs its own representation, "to condemn oneself to be nothing more than the instrument of that which one claims to think" (p. 238, original emphasis).

\section{Acknowledgments}

Thank you to the Department of Applied Social Sciences at the Hong Kong Polytechnic University for the start-up fund that was used to pay for publication of this article. Thank you also to António Vieira for his help throughout the process from submission to publication of this article in Social Inclusion, to anonymous reviewers for their constructive, yet encouraging, comments and suggestions and to my students for providing the commentary to which this article refers.

\section{Conflict of Interests}

The author declares no conflict of interest.

\section{References}

Al Zidjaly, N. (2012). Multimodal texts as mediated actions: Voice, synchronization and layered simultaneity in images of disability. In S. Norris (Ed.), Multimodality in practice: Investigating theory-inpractice-through-methodology (pp. 190-205). London: Routledge.

Albrecht, G. (2015). Rehabilitation. In R. Adams, B. Reiss, \& D. Serlin (Eds.), Keywords for disability studies (pp. 148-150). New York, NY: New York University Press.

Ali, S., \& Kelly, M. (2012). Ethics and social research. In C. Seale (Ed.), Researching society and culture (pp. 58-76). London: Sage.

Bolt, D. (2012). Social encounters, cultural representation and cultural avoidance. In N. Watson, A. Roulstone, \& C. Thomas (Eds.), Routledge handbook of disability studies (pp. 287-297). New York, NY: Routledge.

Bourdieu, P. (1992). The practice of reflexive sociology (the Paris workshop). In P. Bourdieu \& L. J. D. Wacquant (Eds.), An invitation to reflexive sociology (pp. 216-260). Cambridge: Polity Press.

Butler, J. (1997). The psychic life of power: Theories in subjection. Stanford, CA: Stanford University Press.

Butler, J. (2000). Restaging the universal: Hegemony and the limits of formalism. In J. Butler, E. Laclau, \& S. Žižek (Eds.), Contingency, hegemony, universality: Contemporary dialogues on the left (pp. 11-43). London: Verso.

Cameron, C. (2014). Inclusion. In C. Cameron (Ed.), Disability studies: A student's guide (pp. 78-81). London: Sage.

Campbell, F. A. K. (2008). Exploring internalized ableism using critical race theory. Disability and Society, 23(2), 151-162.

Campbell, F. A. K. (2012). Stalking ableism: Using disability to expose 'abled' narcissism. In D. Goodley, B. Hughes, \& L. Davis (Eds.), Disability and social theory: New developments and directions (pp. 212-230). Basingstoke: Palgrave Macmillan.

Chandler, D., \& Munday, R. (2011). A dictionary of media 
and communication. Oxford: Oxford University Press. CRPD. (n.d.). Convention on the rights of persons with disabilities. United Nations. Retrieved from https:// www.un.org/development/desa/disabilities/conven tion-on-the-rights-of-persons-with-disabilities.html

Davies, B. (2003). Shards of glass: Children reading and writing beyond gendered identities. New York, NY: Hampton Press.

Derrida, J. (1976). Of grammatology. Baltimore, MD: John Hopkins University Press.

Dey, I. (1993). Qualitative data analysis: A user-friendly guide for social scientists. London: Routledge.

Eagleton, T. (2008). Literary theory: An introduction. Oxford: Blackwell. (Original work published 1983).

Evans, D. (1996). An introductory dictionary of Lacanian psychoanalysis. London: Routledge.

Fairclough, N. (2015). Language and power. London: Routledge. (Original work published 1989)

Fairclough, N., \& Chouliaraki, L. (1999). Discourse in late modernity: Rethinking critical discourse analysis. Edinburgh: Edinburgh University Press.

Fiske, J. (2006). Television culture. London: Routledge. (Original work published 1987)

Flowerdew, J. (2012). Critical discourse analysis in historiography: The case of Hong Kong's evolving political identity. Basingstoke: Palgrave Macmillan.

Foucault, M. (2002). The archaeology of knowledge. London: Routledge. (Original work published 1969)

Foucault, M. (1995). Discipline and punish: The birth of the prison. New York, NY: Vintage Books. (Original work published 1977)

Ghai, A. (2006). (Dis)embodied form: Issues of disabled women. Delhi: Shakti Books.

Goodley, D. (2012). Jacques Lacan + Paul Hunt = Psychoanalytic disability studies. In D. Goodley, B. Hughes, \& L. Davis (Eds.), Disability and social theory: New developments and directions (pp. 179-194). Basingstoke: Palgrave Macmillan.

GovHK. (2016a). Embracing social inclusion. GovHK. Retrieved from http://www.gov.hk/en/residents/ housing/securityassistance/socialsecurity/Sociallnclu sion.htm

GovHK. (2016b). Services and support for persons with disabilities. GovHK. Retrieved from http://www.gov. hk/en/residents/housing/socialservices/disabilities/ disableservices.htm

GovHK. (2016c). Promote social inclusion (in simplified Chinese). GovHK. Retrieved from http://www.gov. $\mathrm{hk} / \mathrm{sc} /$ residents/housing/socialservices/disabilities/ Sociallnclusion.htm

GovHK. (2016d). Services and support for people with disabilities (in simplified Chinese). GovHK. Retrieved from http://www.gov.hk/sc/residents/housing/social services/disabilities/disableservices.htm

GovHK. (2016e). Promote social inclusion (in traditional Chinese). GovHK. Retrieved from http:// www.gov.hk/tc/residents/housing/socialservices/dis abilities/Sociallnclusion.htm
GovHK. (2016f). Services and support for people with disabilities (in traditional Chinese). GovHK. Retrieved from http://www.gov.hk/tc/residents/housing/social services/disabilities/disableservices.htm

Grue, J. (2009). Critical discourse analysis, topoi and mystification: Disability policy documents from a Norwegian NGO. Discourse Studies, 11(3), 305-328.

Hall, S. (2013). The spectacle of the 'other'. In S. Hall, J. Evans, \& S. Nixon (Eds.), Representation (pp. 215-287). London: Sage. (Original work published 1997)

Hammersley, M. (2014). On the ethics of interviewing for discourse analysis. Qualitative Research, 14(5), 529-541.

Helfer, M. B. (2011). The world unheard: Legacies of antiSemitism in German literature and culture. Evanston, IL: Northwestern University Press.

HKSAR. (2010). Initial report of the Hong Kong special administrative region of the People's Republic of China under the United Nations convention on the rights of persons with disabilities. Retrieved from http:// www.lwb.gov.hk/UNCRPD/Publications/HKSAR\%27s \%20UNCRPD\%20report_Eng\%20(version\%20for\%20 publication).pdf

Hughes, B. (2012). Fear, pity and disgust: Emotions and the non-disabled imaginary. In N. Watson, A. Roulstone, \& C. Thomas (Eds.), Routledge handbook of disability studies (pp. 66-77). New York, NY: Routledge.

Jaworski, A., \& Thurlow, C. (2011). Introducing semiotic landscapes. In A. Jaworski \& C. Thurlow (Eds.), Semiotic landscapes: Language, image, space (pp. 1-40). New York, NY: Continuum.

Jones, J. M. (1972). Prejudice and racism. Reading, MA: Addison-Wesley.

Lash, S. (1994). Reflexivity and its doubles: Structure, aesthetics, community. In U. Beck, A. Giddens, \& S. Lash (Eds.), Reflexive modernization: Politics, tradition and aesthetics in the modern social order (pp. 110-173). Cambridge: Polity Press.

McRuer, R. (2006). Crip theory: Cultural signs of queerness and disability. New York, NY: New York University Press.

McRuer, R. (2007). Taking it to the bank: Independence and inclusion on the world market. Journal of Literary and Cultural Disability Studies, 1(2), 5-14.

Mitchell, D. T., \& Snyder, S. L. (2015). The biopolitics of disability: Neoliberalism, ablenationalism, and peripheral embodiment. Ann Arbor, MI: University of Michigan Press.

Ngai, K. K. H., Wu, S. W. K., \& Chung, J. L. P. (2018). A journey of change: History of disability in Hong Kong 1841-2014. In R. Hanes, I. Brown, \& N. E. Hansen (Eds.), The Routledge history of disability studies (pp. 163-203). London: Routledge.

Oliver, M. (1996). Understanding disability: From theory to practice. Basingstoke: Macmillan.

Quayson, A. (2007). Aesthetic nervousness: Disability and the crisis of representation. Chichester: Columbia University Press. 
Ravaud, J.-F., \& Stiker, H.-J. (2006). Inclusion and exclusion. In G. Albrecht (Ed.), Encyclopedia of disability (pp. 923-928). London: Sage.

Shildrick, M. (1997). Leaky bodies and boundaries: Feminism, postmodernism, and (bio)ethics. New York, NY: Routledge.

Stiker, H.-J. (1997). A history of disability. Ann Arbor, MI: University of Michigan Press.

Stone, E. (1999). Modern slogan, ancient script: Impairment and disability in the Chinese language. In $\mathrm{M}$. Corker \& S. French (Eds.), Disability discourse (pp. 136-147). Buckingham: Open University Press.

Swain, J., French, S., \& Cameron, C. (2003). Controversial issues in a disabling society. Buckingham: Open University Press.

Thomas, C. (2007). Sociologies of disability and illness: Contested ideas in disability studies and medical sociology. Basingstoke: Palgrave Macmillan.

Titchkosky, T. (2007). Reading \& writing disability differently: The textured life of embodiment. Toronto: University of Toronto Press.
UN. (2006). Convention on the rights of persons with disabilities and its optional protocol. United Nations. Retrieved from http://www.un.org/disabilities/doc uments/convention/convoptprot-e.pdf

UN. (2012). Concluding observations on the initial report of china, adopted by the committee at its eighth session, 17-28 September 2012: Committee on the rights of persons with disabilities (CRPD/C/CHN/CO/1). The United Nations. Retrieved from www.lwb.gov.hk/UNCRPD/Publications/CRPDC-CHN-CO-1_en.doc

Van Dijk, T. A. (1993). Principles of critical discourse analysis. Discourse \& Society, 4(2), 249-283.

Van Leeuwen, T. (2005). Introducing social semiotics. London: Routledge.

Wodak, R. (2004). Critical discourse analysis. In C. Seale, G. Gobo, J. F. Gubrium, \& D. Silverman (Eds.), Qualitative research practice (pp. 185-201). London: Sage.

Žižek, S. (1989). The sublime concept of ideology. London: Verso.

\section{About the Author}

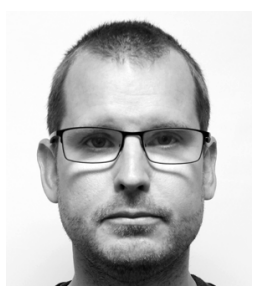

Alex Cockain is an Assistant Professor in the Department of Applied Social Sciences at the Hong Kong Polytechnic University. He teaches courses relating to anthropology, media theory and qualitative research methods. 